\section{Homens e mulheres indígenas contemporâneos da região do Rio Negro, Amazonas}

\author{
Dupô - Justino Sarmento Rezende ${ }^{1}$
}

DOI: http://dx.doi.org/10.20435/tellus.v0i31.411

\section{INICIANDO A CONVERSA}

Essa é uma visão breve sobre como eu consigo compreender os povos indígenas de nossa região do Rio Negro, como nos sentimos como indígenas dos tempos atuais e o que mexe com as nossas vidas e culturas.

\section{DESDE QUANDO SABEMOS QUE SOMOS PESSOAS HUMANAS?}

Quem somos nós pessoas humanas? O que fazemos nesse mundo? Para onde caminhamos? De onde viemos? Por que vivemos assim? São perguntas que todos os povos fazem. Nossos sábios explicam sobre nossa existência, nosso ser/fazer. Para tanto realizam meditações diariamente. Os benzimentos de curas e de proteção, cantos/danças rituais dão significados importantes para nossa vida.

Nossos sábios entendem o funcionamento do mundo humano e o mundo do entorno. Com poderes de sua mente transitam e dialogam com os seres de outros mundos, com os espíritos, antepassados, seres da saúde, da doença e de curas. Eles conhecem o funcionamento dos ciclos da vida humana, da natureza e outros seres vivos. As festas rituais estão ligadas a tais ciclos. Sábios Bayaroá (mestres de danças), Kumuâ (pensadores) aprofundam os signifi cados de nossas vidas. Eles promovem o que faz bem para nossa vida, nosso coração e nosso nome.

\footnotetext{
${ }^{1}$ Salesiano. São Gabriel da Cachoeira, Amazonas, Brasil.
}

\section{Sobre o autor:}

É indígena do povo Utãpinopona-Tuyuka, nascido na aldeia Onça-Igarapé (1961), distrito de Pari-Cachoeira, município de São Gabriel da Cachoeira, Amazonas. É salesiano e padre. Graduado em Filosofia (UCB/DF); Bacharél em Teologia (FTNSA/SP) e Mestre em Educação (UCDB/MS). E-mail: justinosdb@yahoo.com.br 
Basariwi (Casa Ritual)2 é o lugar da vida, da festa, dos estudos, das meditações, narrativas de histórias, escolhas e decisões políticas diante dos desafios internos e externos. As festas rituais mexem com a vida, sentimentos, sentido de pertença a um determinado povo. Eu já sentei próximo aos Kumuâ e Bayaroá, fumei cigarro benzido e defumei meu corpo para ser protegido dos males, comi o ipadu (feito de folha de coca), tomei caapi (bebida alucinógena).

Os benzimentos são recebidos ao longo de todo ciclo da vida. Eles dão sustentabilidade às nossas vidas, fazem-nos sentir bem como pessoa, conviver bem com as pessoas e com outras vidas do mundo ao nosso redor. Há pessoas especializadas em nossas espiritualidades indígenas que meditam, refletem, curam, dançam, discursam e ritualizam a vida. Na atualidade as nossas espiritualidades indígenas se encontram com outras espiritualidades de origem cristã e influenciam fortemente na construção das vidas e histórias dos povos indígenas atuais.

Na Casa Ritual ouvi as narrativas de histórias sagradas nas madrugadas. Toquei e dancei cariço junto com os jovens e adultos, acompanhado pelas mulheres. Fiquei suado, cansado, achei graça, assobiei junto com todos. Tomei cuias de caxiri ${ }^{3}$ oferecidas pelas mulheres irmãs maiores e menores, cunhadas, tias, avós.

Virei o dia e a noite, participando das festas. Admiro a delicadeza com a qual os Bayaroâ preparam as plumas sagradas, de arara, garça e outros ornamentos para serem colocadas na cabeça, nas cinturas, braços, pernas. Realizam bonitas pinturas faciais e corporais antes de cantar/dançar. As mulheres e os homens pintam-se com jenipapo realçando com traçados escuros nos corpos.

Os ecos das vozes masculinas e femininas, sons de instrumentos, ritmos, chocalhos, assobios de jovens e gargalhadas das mulheres, músicas cantadas e dançadas enchem o espaço da Casa Ritual e extravasam para aldeia toda. Os sons encarnam-se no profundo de nosso ser. Após as festas as falas, músicas, vozes, sons continuam ressoando dentro da gente por vários dias.

Outras músicas são criadas e cantadas no exato momento da festa pelos homens e mulheres. Falam da vida atual, do trabalho, da caça, da pesca, da vida familiar, do parentesco, da amizade, do enamoramento e casamento.

As paradas entre as partes das danças são importantes para contar piadas, dar boas gargalhadas, beber gostosas cuias de caxiri (bebida fermentada).

\footnotetext{
${ }^{2}$ Aqui na região do Rio Negro, como em outras regiões do Brasil, para estas Casas Rituais, os colonizadores denominaram-se de Malocas. Assim nós indígenas utilizamos até o início da década de 2000 quando a FOIRN decidiu utilizar o termo Casas dos Saberes.

${ }^{3}$ Para as festas rituais a massa que servirá para a preparação do caxiri é benzida para que quem dela beber consiga conviver com alegria, cantar bem, dançar bem e falar bem.
} 
As mulheres circulam cantando e oferecendo bebidas, outras acompanham os seus pares nas danças.

A Casa Ritual e as pessoas entram em movimento e transformam nossa vida, despertam outros sentidos existenciais. Quando estou ai sinto-me conectado com as personalidades míticas e com meus antepassados. Cada povo vive sua própria cultura, sem deixar de construir os relacionamentos interétnicos e interculturais. Aprendemos respeitar nossa biodiversidade que é outra vida dialogando com os seres humanos.

Essas riquezas humanas e ambientais criam cobiças, ciúmes, desejos de apropriação de nós e de nossos saberes. Diversos não indígenas ("brancos") estudaram nossas vidas, nossas culturas, nossos costumes, nossas riquezas, nossos defeitos. Falaram de nós, sem sentir no coração o que é ser um originário dessas culturas.

\section{HÁ NECESSIDADE DE COMPREENDERMOS SOBRE NOSSA CAPACIDADE DE CUIDAR DA VIDA?}

Nós possuímos modos próprios de cuidar da vida das pessoas, das vidas do universo e outros seres que fazem parte do nosso convívio. Até hoje muitas famílias vivem em suas aldeias, pequenas comunidades, onde todos se conhecem e se comprometem com o cuidado da vida de todos. Há momentos de partilha da alimentação, dos trabalhos, parada quando falece alguém da comunidade, parada para festa, para viagens, para reuniões. Cada povo transmite os valores antigos construídos desde os antepassados e deve perpetuar nas histórias.

Sem dúvida que a educação está diretamente relacionada com a época em que vivemos. Os adultos, jovens e crianças criam estilos de vida próprios. $\mathrm{Na}$ atualidade aprendemos também contribuições de outras culturas, aprendemos outras línguas, outros conhecimentos, músicas, ritmos, outros costumes. As crianças indígenas, hoje, em muitos lugares crescem brincando com jogos eletrônicos. Deixam de lado atividades lúdicas tradicionais, nadar, correr, etc.

Muitos jovens e os adolescentes utilizam celulares, com eles ouvem músicas, registram e divulgam os acontecimentos; onde tem sinal de telefone conversam com pessoas que estão muito distante. Sem dúvidas, também são atingidos pelos fatores negativos: individualismo, surdez, falta de comunicação direta pessoa a pessoa.

Somos povos dinâmicos e nas nossas vidas surgem muitas necessidades que se originam das culturas em processo de globalização. Não conseguimos 
satisfazer todas as necessidades e assim surgem em nós sentimentos de fracasso, sofrimento, ilusão, decepção, etc. Há necessidade de termos profissionais qualificados e capacitados para o acompanhamento às pessoas atingidas por problemas atuais. Para os problemas atuais nossos tradicionais benzimentos não curam. Os pais, os avós, os educadores, professores e demais profissionais preocupam-se em cuidar das vidas humanas. As rápidas mudanças de épocas e transformações geradas pelo próprio ser humano atinge diretamente a raça humana. A educação nesse sentido não é somente a transmissão dos saberes de um povo para seus filhos, mas hoje implica estudar os comportamentos humanos de seus filhos e filhos para buscar respostas mais adequadas ao ritmo de desenvolvimento e crescimento deles. Se olharmos a situação de cada pai e de cada mãe constatamos que ninguém os preparou para ser mãe e pai para os filhos com perfis atuais. Diga-se de passagem, que nem todos estão preparados para cuidar da vida indígena infantil, adolescente e juvenil.

\section{SERÁ QUE COMPREENDEMOS QUE A CONSTRUÇÃO DAS SABEDORIAS ACONTECE ENTRE OS POVOS INDÍGENAS?}

Cada povo indígena é herdeiro das sabedorias construídas por seus avós míticos e humanos. Nós herdamos histórias humanas, conhecimentos, práticas de vida, modos de relacionamentos com a biodiversidade.

Os desafios de contextos históricos contemporâneos exigem de nós a construção de novas sabedorias, conhecimentos e novos estilos de bem viver. Os nossos pensamentos, sentimentos, nossa vontade, nosso interior, atitudes e nossos comportamentos mudam, também.

A cada período de três anos eu visito meus parentes, nos lugares distantes dos centros urbanos. Lá eu consigo enxergar outras dimensões da minha vida. No ano de 2011 visitei meus parentes que estão no lado colombiano. Conforme nossa tradição eles nos acolheram muito bem. Ofereceram quinhapira, peixe moqueado, manicoera e chibé.

Ao anoitecer sentaram-se na Casa Ritual e conversaram com os meus colegas de viagem. Num clima descontraído e tranquilo, dentro da casa iluminada pelo fogo, conversavam sobre coisas sérias e intercalavam com histórias engraçadas, piadas e achavam graça à vontade. As crianças, jovens e as mulheres deitadas em suas redes ouviam as trocas e construção de conhecimentos.

Eu estava deitado na rede e acompanhava que ali eram produzidos bons discursos, boas reflexões sobre as mudanças de épocas e o que nós seres humanos devemos fazer no mundo atual. Conversavam sobre o mundo do passado, como viviam os homens e as mulheres, como tratavam outras pes- 
soas, como lidavam com os conhecimentos, como se construíam os relacionamentos entre diferentes povos, etc. Depois voltavam a falar das pessoas dos tempos atuais. Analisavam nossa vida atual e nossas atitudes de pessoas que estudamos nas escolas e universidades.

Eu olhava para mim mesmo a partir daqueles lugares. Embora eu seja um indivíduo que se dedica a estudar e falar das culturas indígenas eu estava muito distante dos conteúdos que se vive naqueles lugares. Eu me senti "estranho", pois estava com mentalidade e postura ocidentalizada. A tradição tuyuka ensina que um visitante deve conversar com os moradores do lugar, contar suas histórias e ouvir as histórias deles. No encontro das informações que surgem outras reflexões que apontam novas perspectivas históricas.

Os meus parentes que há tempo não me viam, esperavam que eu lhes contasse muitas novidades. Esperavam escutar como era a minha vida, os lugares onde eu trabalho; como outros padres vêm meu trabalho; como outros povos indígenas vêm a minha pessoa, etc. A partir disso que eles ofereceriam sugestões de como eu deveria conduzir a minha vida e meus trabalhos.

Meus parentes sábios com suas conversas simples, alegres e descontraídas desconstroem minhas palavras complicadas e teóricas que eu aprendi nas universidades. Os modos de vida deles são lições de como podemos construir, transmitir e aprender questões importantes da vida, com falas boas, alegres, com gargalhadas. É um desafio para eu chegar a esse nível de harmonia, equilíbrio e sabedoria.

\section{5 É IMPORTANTE COMPREENDER AS DIVERSIDADES CULTURAIS EM NOSSA REGIÃO?}

As diversidades culturais são riquezas e patrimônios nossos, de nossa região e do mundo. A pertença a um povo específico garante a identidade e diferença diante de outros povos. A identidade mostra quem sou eu, como eu estou construindo minha vida e minhas histórias. A diferença ajuda-me a afirmar que eu sou eu porque existem os outros, com seus conhecimentos, com suas histórias, com suas origens, etc. Nossas identidades têm muito a ver com nossa pertença comunitária, étnica e localização em um território.

As nossas histórias mudam continuamente e cada vez mais são aceleradas. Dentro dessas dinâmicas construímos nossas vidas. Interagimos com muitas culturas, línguas, costumes, saberes, projetos, gêneros. Na atualidade nossas histórias têm alcance grande e estamos presentes em diferentes setores sociais, instituições, religiões, igrejas, escolas, famílias, comunidades, costumes e tradições indígenas. 
Em eventos promovidos pela Federação das Organizações Indígenas do Rio Negro (FOIRN) eu costumo estar com pessoas de diferentes regiões, cada um fala a sua própria língua, fala e acha graça, discursa e debate. Eu entendo que é para autoafirmar-se e diferenciar-se. Serve para demarcar a diferença. Para um indígena e padre acostumar-se dentro dessa nova realidade levou um tempo. Precisei exercer minha paciência, serenidade, calma, dar tempo ao tempo. No momento certo traduzem o que falaram em língua portuguesa, que é um meio de comunicação que facilita a compreensão entre todos os povos do rio Negro. Há quem diga que o outro tem que aprender a língua nossa. São discursos fortes, com tom de imposição. Eu sei que ninguém será capaz de aprender todas as línguas dos vinte e três (23) povos da nossa região, nem todas as pessoas vão querer aprender todas as línguas, a não ser que tenha objetivo para alcançar tal meta.

Nós vivemos nas sociedades plurais e complexas. Aprendemos a dialogar com as pessoas que possuem complexas posturas pessoais e institucionais. As influências e interferências culturais são contínuas e com todas as culturas. Os nossos saberes e os saberes dos outros se misturam. As ideias e ideologias são híbridas e mestiças. Hoje em dia, é cada vez mais difícil afirmar como "culturas puras". As nossas culturas indígenas contemporâneas carregam dentro de si as marcas de muitas culturas, no estilo de vestir, utensílios, materiais de navegação, instrumentos de caça e pesca, nossas línguas faladas são ricas de expressões e significados que proveem de outras línguas.

\section{POR QUE SOMOS POVOS ESPECÍFICOS E DIFERENTES?}

Nós e outros e vice-versa estamos construindo nossas histórias desde os nossos antepassados seres-divinos-espíritos até chegarmos ao momento atual do nosso processo de humanização, indigenização. Existem distanciamentos e proximidades com os nossos antepassados. Cada povo construiu ao longo de suas histórias os modos próprios de relações sociais, com as pessoas de sua comunidade e com as de outros povos. As pessoas adaptam-se aos inúmeros desafios das realidades, criam modos de viver a vida, atitudes diante do mundo e das pessoas.

Os processos de produção, reprodução, construção, desconstrução, significação, ressignificação dos conhecimentos tradicionais, modernos, pós-modernos, etc., acontecem continuamente nas culturas do rio Negro, através das variadas formas de contatos com outras culturas, outros saberes, línguas, disputas, projetos e ações. Nós e outros, nossos saberes e saberes dos outros, nossos projetos 
de vida e projetos dos outros, interagem continuamente, superando os isolamentos das comunidades. Hoje os costumes, tradições, novidades, problemas são universais. Agora, sim, podemos dizer que o mundo é uma aldeia global.

Os pesquisadores não indígenas que andaram muito tempo atrás em nossas regiões encontraram indígenas bem diferentes do que os de hoje. Eles escreveram como eles nos viam, anotavam e interpretavam. Mais recentemente, nós mesmos começamos escrever (1980s.) sobre nossas culturas, nossas tradições, costumes, nossos saberes. Alguns escritores escreveram em suas próprias línguas. São obras escritas a partir dos ensinamentos recebidos dos pais e avós. As memórias pessoais e coletivas são fontes que inspiram a elaboração de seus escritos. São ensinamentos guardados no coração. São também frutos de observação e prática da cultura.

Nós indígenas afirmamo-nos ser indígenas de um determinado povo, pois conhecemos os critérios de pertencimentos, mas também trazemos em nossas vidas marcas das identidades de outros povos indígenas e não indígenas. Somos indígenas com ideais novos, outras necessidades, outras trajetórias de vida, outras conquistas, derrotas. Hoje, nos recantos mais afastados dos centros urbanos, é um fato, encontrar antenas para localização de satélites e acessar as redes sociais que nos fazem construir novas aldeias, novos grupos, outros sitios [sites/nets]. Criam-se ali grupos de uma determinada região e grupos de afinidades. A partir desses sites pode-se interagir com pessoas que estão em online em qualquer parte do planeta terra, noticiando, informando e partilhando os acontecimentos. Acreditava-se que esse mundo é virtual. Mas hoje já podemos dizer que é um mundo real, onde se cria culturas no cotidiano, atinge profundamente a vida de um ser.

\section{COMO FORAM CONSTRUÍDAS NOSSAS SOCIEDADES INDÍGENAS?}

Cada povo indígena organiza a sua sociedade, sua economia, as alianças com outros povos, etc. Em geral nós estamos organizados por grupos familiares que facilitam convivência respeitosa entre irmãos maiores e menores, primeiros (chefes) e últimos (servos).

A construção de nossas histórias é movida por ideologias desde as nossas origens, momento das emergências até o presente. As nossas políticas são construídas na tensão entre as forças humanas e forças da natureza. Nossas ideologias indígenas são carregadas de humanismo, pensamentos, filosofias, conceitos, preconceitos, disputas de espaços, guerras, etc. 
Em nossa região do Rio Negro, AM, no dia 30 de abril de 1987 foi criada a Federação das Organizações Indígenas do Rio Negro (FOIRN) para marcar nova fase da organização social e política de nossos povos: reconstrução e revitalização das culturas; fortalecimento das ideologias, da autonomia e autodeterminação; construção das alianças; união dos povos indígenas; construção de novas perspectivas da vida; construção de objetivos comuns; superação das divisões tradicionais entre os diferentes povos indígenas da região; construção de alianças com os partidos políticos, administração pública; enfim, busca de construir respostas para os problemas sociais da nossa região.

As lutas deram resultados em demarcação e homologação das terras indígenas. No período pós-demarcação veio outra tarefa: implantação de projetos de sustentabilidade e auto-sustentabilidade, construção das escolas indígenas; implantação de programas de ensino superior para mais perto e dentro das comunidades indígenas.

Nós povos indígenas avançamos também no campo da política partidária. Como cidadãos brasileiros participamos com nossos deveres de votar e com direito de sermos votados. Articulamos e costuramos alianças para traçarmos novas perspectivas de vida. Muitos parentes são filiados aos diversos partidos políticos. Dentro desses partidos com suas ideologias próprias tornamo-nos adversários e muitos se tornam inimigos. As nossas ideologias indígenas nem sempre conseguem influenciar efetivamente nas políticas partidárias.

Apostamos efetivamente nas nossas capacidades de pensar, trabalhar, dialogar, negociar, interagir com diferentes projetos de trabalho. Nós estamos mais preparados para assumir certos trabalhos que antes não estavam ao nosso alcance. Sem dúvida, devemos contar com a colaboração de pessoas que nos ajudam a pensar, discernir, elaborar projetos, gerenciar e gerir recursos humanos, materiais e financeiros.

A construção de nossa autonomia precisa ser acompanhada pelo processo de descolonização de nosso próprio ser, questionar nosso mundo humano, os modos como construímos o mundo até agora, questionar as histórias que os outros construíram para nós. Em outras palavras devemos pensar diferente, posicionar ativamente frente às ideologias dominantes colonizadoras. Significa apoderar-se das ideologias do diálogo de iguais, diálogos de diferentes, não de desiguais nem de inferiores. Assumir nosso papel de sujeitos das histórias, pensar como indígenas, assumir e fortalecer nossa filosofia intracultural para construirmos uma filosofia intercultural. Na construção da filosofia intracultural, procurar descolonizar nossos discursos indígenas, pois dentro de muitas culturas indígenas existem muitos componentes colonizadores e dai que somos em muitos aspectos indígenas colonizadores. 


\section{A CONVERSA CONTINUARÁ!}

É importante olhar para os povos do rio Negro a partir dos olhares do presente; dos olhares indígenas e também dos olhares não indígenas. Eu vejo que não existe uma ruptura total com o passado. Nós indígenas vivemos transitando nos mundos muito antigos e nos mundos novos do nosso tempo. O passado e o presente não são polos independentes.

Cada tema apresentado merece um longo tempo de aprofundamento, pois são temas complexos como são complexas as culturas humanas de nossa região. O que está posto aqui serve para provocar nossos modos de pensar e repensar sobre os processos de historicidade indígenas e não indígenas. As nossas culturas representam muito mais do que possamos dizer, nós somos muito mais do que conseguimos dizer de nós e muito mais do que o outro consegue enxergar e dizer algo sobre nós.

\section{REFERÊNCIAS}

BARTH, Fredrik. Guru, o iniciador e outras variações antropológicas. Tradução de John Cunha Comerford, Rio de Janeiro: Contra Capa Livraria, 2000.

BHABHA, Homi. O local da cultura. Belo Horizonte: UFMG, 1998.

CANCLINI, Nestor Garcia. Culturas híbridas. 2. ed. São Paulo: Edusp, 2003.

CARNEIRO, Manuela. Etnicidade: da cultural residual mas irredutível. In: CARNEIRO, Manuela (Org.). Antropologia do Brasil. São Paulo: Brasiliense, 1986.

GEERTZ, Clifford. A interpretação das culturas. Rio de Janeiro: Guanabara Koogan, 1989.

GRUZINSKI, Serge. O pensamento mestiço. São Paulo: Companhia das Letras, 2001.

LARAIA, Roque de Barros. Cultura, um conceito antropológico. 11. ed. Rio de Janeiro: Jorge Zahar, 1997.

OLIVEIRA FILHO, João Pacheco. Uma etnologia dos "índios misturados": situação colonial, territorialização e fluxos culturas. In: OLIVEIRA FILHO, João Pacheco (Org.). A viagem de volta. Rio de Janeiro: Contra Capa Livraria, 1999. p. 11-40.

REZENDE, J. S. Educação na visão de um Tuyuka. Manaus: FSDB, 2010.

Escola Indígena Municipal Utãpinopona-Tuyuka e Construção da Identidade Tuyuka. 2007.371f. Dissertação (Mestrado em Educação) - Universidade Católica Dom Bosco, Campo Grande, MS, 2007.

SEMPRINI, Andrea. Multiculturalismo. Tradução de Laureano Pelegrini. Bauru: EDUSC, 1999. 